\title{
Health perceptions of young adults living with recessive limb-girdle muscular dystrophy
}

\author{
Anna-Carin Aho, Sally Hultsjö and Katarina Hjelm
}

\section{Linköping University Post Print}

\section{Tweet}

N.B.: When citing this work, cite the original article.

Original Publication:

Anna-Carin Aho, Sally Hultsjö and Katarina Hjelm, Health perceptions of young adults living with recessive limb-girdle muscular dystrophy, 2016, Journal of Advanced Nursing, 1-11.

http://dx.doi.org/10.1111/jan.12962

Copyright: Wiley: 12 months

http://eu.wiley.com/WileyCDA/

Postprint available at: Linköping University Electronic Press

http://urn.kb.se/resolve?urn=urn:nbn:se:liu:diva-126555 
Health perceptions of young adults living with recessive limb-girdle muscular dystrophy

\section{Running head}

Health perceptions of young adults with muscular dystrophy

\section{Authors}

Anna Carin AHO, RN, PhD student ${ }^{1}$, Sally HULTSJÖ, PRN, PhD, Senior Lecturer ${ }^{2}$, Katarina HJELM, SRNT, PhD, Professor ${ }^{3}$

${ }^{1}$ Department of Health and Caring Sciences, Linnaeus University, Växjö, Sweden.

${ }^{2}$ Psychiatric Clinic, County Hospital, Ryhov, Jönköping, Sweden.

${ }^{3}$ Department of Social and Welfare Studies, University of Linköping, Campus Norrköping, Sweden. 


\section{Corresponding author}

\section{Anna Carin Aho}

Department of Health and Caring Sciences,

Linnaeus University,

35195 Växjö,

Sweden.

Telephone: $+46(0) 735876635$.

E-mail: anna.carin.aho@1nu.se

\section{Acknowledgements}

The authors would like to acknowledge Alan Crozier for language review of this article.

\section{Conflicts of interest}

No conflict of interest has been declared by the authors.

\section{Funding}

This research received no specific grant from any funding agency in the public, commercial, or not-for-profit sectors. 


\section{ABSTRACT}

Aim: To describe health perceptions related to sense of coherence among young adults living with recessive limb-girdle muscular dystrophy.

Background: Limb-girdle muscular dystrophy refers to a group of progressive muscular disorders that may manifest in physical disability. The focus in healthcare is to optimize health, which requires knowledge about the content of health as described by the individual.

Design: A descriptive study design with qualitative and quantitative data were used.

Method: Interviews were conducted between June 2012 - November 2013 with 14 participants aged 20-30 years. The participants also answered the 13-item sense of coherence questionnaire. Qualitative data were analysed with content analysis and related to self-rated sense of coherence.

Findings: Health was viewed as intertwined physical and mental well-being. As the disease progressed, well-being was perceived to be influenced not only by physical impairment and mental strain caused by the disease but also by external factors, such as accessibility to support and attitudes in society. Factors perceived to promote health were having a balanced lifestyle, social relations and meaningful daily activities. Self-rated sense of coherence varied. The median score was 56 (range $37-77$ ). Those who scored $\geq 56$ described to a greater extent satisfaction regarding support received, daily pursuits and social life compared with those who scored $<56$.

Conclusion: Care should be person-centred. Caregivers, with their knowledge, should strive to assess how the person comprehends, manages and finds meaning in daily life. Through dialogue, not only physical, psychological and social needs but also health-promoting solutions can be highlighted. 
Keywords: LGMD2, chronic diseases, disability, nursing, sense of coherence, SOC-13 
SUMMARY STATEMENT

Why is this research needed?

- Young adults diagnosed with recessive limb-girdle muscular dystrophy need support from a multidisciplinary healthcare team to optimize their health and there is currently no cure available.

- Understanding the individual's health perceptions is essential for achieving good health in cooperation with caregivers, but there is a gap in knowledge about the young adults' perspectives.

- Increased understanding of this group of care recipients can be reached by describing young adults' health perceptions related to self-rated sense of coherence when living with limb-girdle muscular dystrophy.

\section{What are the key findings?}

- Health was viewed as intertwined physical and mental well-being and related to:

○ a balanced lifestyle regarding physical activity/food habits; social life; and daily activities.

- Well-being was perceived to be affected by physical and mental consequences due to the disease but also by external factors, such as accessibility to support and other people's attitudes.

- Self-rated sense of coherence varied and a high score was achievable despite severe physical disability. 


\section{How should the findings be used to influence practice?}

- Care for individuals diagnosed with limb-girdle muscular dystrophy should be person-centred, viewing the individual not only as a unique body but also as a unique person.

- Nurses, in dialogue with the person, should identify physical, psychological and social needs and focus on how well-being can be promoted for the single person.

- Using the sense of coherence questionnaire may start a dialogue to assess how the person comprehends, manages and finds meaning in everyday life and highlight support needed to promote health. 


\section{INTRODUCTION}

Young adults, aged 18-30 years, are in a self-reflective period in life when various possibilities in love, education, work and homemaking are explored (Arnett 2004), but those living with physical disability are less likely than their peers to get married, achieve higher education, be employed and have independent living, which may negatively affect health and well-being (Blum 2005). Young adults living with muscular dystrophy (MD) may have to cope with physical disability and increased dependency on other people. The recessive limbgirdle muscular dystrophies (LGMD2) comprise a group of progressive inherited muscular disorders that are present worldwide (Rosales \& Tsao 2012). Currently, there is no cure available and the focus of healthcare must be on optimizing health and well-being. Understanding experiences of health and illness constitutes a core in nursing (Meleis 2011). Thus, in order to reach the goal of good health for young adults diagnosed with LGMD2, knowledge is needed about health perceptions from the individual's perspective, but no previous study has been found focusing on this. Moreover, to experience health, people need to comprehend their lives and be understood by others and also perceive that life is manageable and meaningful, which means achieving a sense of coherence (SOC) (Antonovsky 1987). How daily life is described as being comprehended, managed and found meaningful among young adults living with LGMD2 is presented in a previous study (Aho et al. 2015). This study focuses on the young adults' own health perceptions.

\section{Background}

LGMD2 may manifest in loss of walking ability and difficulty in managing daily activities. In some of the subtypes of LGMD2, cardiac and respiratory complications may arise (Rosales \& Tsao 2012). Thus, LGMD2 can develop into severe physical impairment, negatively affecting 
health over time and the individual therefore needs support from a multidisciplinary healthcare team as the disease progresses. In order to optimize health, the focus has been on the importance of genetic diagnosis (Narayanaswami et al. 2014); management including emotional/physical support and treatment of complications (Mahmood \& Xin Mei 2014); and physiotherapy including stretching to prevent contractions and promote walking (Nigro et al. 2011). However, health from the perspective of young adults living with LGMD2 has not previously been described.

The goal for healthcare and medical service is good health (SFS 1982:763). There are different theories of health, however and two main perspectives are evident. The biostatistical perspective views health as the absence of disease (Boorse 1977) whereas the holistic perspective involves the whole person and views health, for instance, as either the ability to reach vital goals (Nordenfelt 2007), or as health-related well-being in combination with abilities (Tengland 2007). In nursing, the individual should be viewed as a unity consisting of body, soul and spirit and the focus is on how to support the individual to enhance adaptation capability and to achieve health (Meleis 2011). Each person at a given point of time can also be seen somewhere along a health-disease continuum. Where on the continuum a person is located depends on how the person perceives daily life when it comes to comprehensibility, manageability and meaningfulness, which can be measured with the SOC questionnaire (Antonovsky 1987).

Understanding health from the individual's perspective is a prerequisite for reaching the goal of good health in cooperation with the healthcare team. Health among young adults has been described in general (Breiner et al. 2014, Park et al. 2014, Ainsworth \& Ananian 2013) and 
from the perspectives of living with various disabilities (Blomquist 2006) or diseases

(Patterson et al. 2012, Jetha et al. 2015, Ferris et al. 2015). However, while previous research on MD has focused on children and/or parent proxy reports (Lim et al. 2014, Bray et al. 2010, Opstal et al. 2014) adolescents (Pehler \& Craft-Rosenberg 2009, Parkyn \& Coveney 2013), adults (Boström \& Ahlström 2004) or young men living Duchenne MD (Abbott \& Carpenter 2014, Dreyer et al. 2010), there is a gap in knowledge about health perceptions among young adults living with LGMD2.

\title{
THE STUDY
}

\begin{abstract}
Aim
The aim of the study was to describe health perceptions related to sense of coherence among young adults living with recessive limb-girdle muscular dystrophy.
\end{abstract}

\section{Design}

This study has a descriptive design, using both qualitative data from interviews to describe the individuals' health perceptions and quantitative data from the self-administered SOC-13 questionnaire to describe the individuals' sense of coherence. Interviews were chosen as this gives the participants an opportunity to respond with their own words (Patton 2015). The SOC-13 questionnaire was used to describe where on the health-disease continuum the participants were located (Antonovsky 1987) and to mirror qualitative data. The SOC has previously been shown to be related to perceived health, especially mental health. The stronger the SOC, the better the perceived health was described (Eriksson \& Lindström 2006). 
Thus, by combining qualitative and quantitative data, a more complete picture of the concept of health as described by the participants can be achieved (Patton 2015).

\section{Participants}

A purposeful sampling procedure was used (Patton 2015). Inclusion criteria were persons aged 18 to 30 years and diagnosed with LGMD2. Those who could not participate in the study due to cognitive impairment or inability to speak Swedish were excluded.

The participants $(N=14)$ were recruited from hospitals in three different healthcare regions $(N=10)$, from the association Neuro Sweden $(N=1)$ and from a web-based association for people with disabilities $(N=3)$. The managers of the hospital clinics and the chairman of Neuro Sweden were given written information about the study and gave their written approval for it. A letter including information about the study was then sent by healthcare professionals and key members in Neuro Sweden to potential participants. The first author also sent the information letter by e-mail to members of the web-based association who could be included. Those who accepted participation in the study sent contact information to the first author, who telephoned them to arrange the interviews.

\section{Data collection}

Data were collected between June 2012 - November 2013. Health perceptions were investigated by an open interview question: 'Can you describe what health means to you?' This question was part of longer individual interviews conducted by a nurse (first author) about young adults' experiences of living with LGMD2 (Aho et al. 2015). All the interviews were held at the respondent's home except one held at the respondent's work and one in a 
neutral place. Each interview lasted about one hour. The interviews were recorded and transcribed verbatim. Data collection and analysis proceeded concurrently and interviews were held until no new information came forth in the data analysis and this determined the sample size (Patton 2015).

At the end of the interview, the participants were asked to fill in the self-administered SOC-13 questionnaire developed by Antonovsky (1987). The concept of SOC has been operationalized in this instrument. The questionnaire contains questions measuring comprehensibility, manageability and meaningfulness in daily life. The instrument has been shown to be reliable, valid and cross-culturally applicable (Eriksson \& Lindström 2005). The Swedish translation of the instrument (Antonovsky 2005) has been found reliable, with a Cronbach's alpha of 0.89 (Olsson et al. 2009). Previously, it has been used in the Swedish context for people living with various chronic diseases (Sandén-Eriksson 2000, Falk et al. 2007, Delgado 2007, Caap-Ahlgren \& Dehlin 2004). Each answer in the questionnaire is marked on a 7-point Likert scale. The lowest score is 13 and the highest is 91 . A high score represents a strong SOC (Antonovsky 1987). The questionnaire was used with permission from the copyright holder.

\section{Ethical considerations}

Ethical approval for the study was obtained from a regional ethics board. The study was performed with written informed consent and in accordance with the Declaration of Helsinki (WMA 2013). The participants received written and oral information about the study. Collected data were anonymized, coded and stored in a locked space to which only the first author had access. 


\section{Data analysis}

Firstly, qualitative interview data were analysed using inductive content analysis according to Mayring (2000) (Table 1). The interview text was initially read several times to get a sense of the whole. The text was then read line by line. Content units were marked and coded with names as closely as possible to the text. The codes with similar meanings were brought together into subcategories. The subcategories were then compared and contrasted and those with similar content were abstracted into main categories in a dynamic process. Data analysis and content in categories were continuously discussed with the co-authors until coder agreement was reached (Mayring 2000). Secondly, quantitative data from the items of the SOC-13 questionnaires were calculated (Bengel et al. 1999), analysed with descriptive statistics and presented in median and range. Thirdly, the qualitative interview data were related to the quantitative data by reading each interview in the light of the individual's selfrated SOC and identifying various patterns of perceptions in the text which may illustrate different perspectives of the individual's SOC.

\section{Rigour}

The participants came from different healthcare regions in Sweden and represented various experiences of the disease, which increased the trustworthiness of the study (Patton 2015). The interviews were held at a place chosen by the participants and conducted by the first author, who had no professional or personal relation to the participants. The interviewer is, however, experienced in the care of individuals diagnosed with MD as an anaesthetic/intensive care nurse and being a next of kin to a person with the diagnosis. Qualitative data analysis and content in the categories were evaluated to confirm its relevance 
by the co-authors, who are experienced nurses and researchers trained in qualitative content analysis, which enhances the credibility of the study. Dependability was ensured by clearly describing the research process and by presenting categories and subcategories with illuminative quotations (Patton 2015).

\section{FINDINGS}

Fourteen respondents, eight females and six males, aged 20-30 years (median $=25$ ), participated in the study. The median age when symptoms of LGMD2 first appeared was 11 years. Characteristics of the participants related to self-rated SOC are presented in Table 2. Based on the participants' descriptions, three groups were found regarding dependency on human aid and assistive devices to manage daily life: those who were independent, those who were in transition from being independent to become more dependent and those who were dependent. Living an independent life and/or having a job indicated a strong SOC.

\section{Perceptions of health}

Three categories concerning perceptions of health were developed through qualitative data analysis (Table 1). The categories were: health viewed as well-being; health influenced by the disease and its consequences; and factors perceived to promote health.

\section{Health viewed as well-being}


Health was perceived as physical and mental well-being and a sense of living a good life with the disease as part of life.

\section{Physical and mental well-being}

Health was viewed as a subjective experience of feeling good and being satisfied with life. It was described in terms of intertwined physical and mental well-being. Health was also associated with a sense of feeling alert and fresh, with the ability to manage what one is supposed to manage. The importance of mental well-being, rather than physical abilities, was emphasized by some of the participants. The perception was that a subjective experience of feeling healthy can be obtained regardless of physical impairments:

it's both physical and mental health ... they go hand in hand ... health is much more than being well or not well ... it's being really satisfied with yourself and feeling good ... content with your life (10)

\section{Well-being with the disease as part of life}

Although the disease influenced daily activities, it did not always have to be in focus. Thus, several of the participants expressed a sense of having learned to live with the disease as a normal part of life. Some of the participants felt well-being, apart from (or in spite of) the disease:

I still think I'm healthy apart from this thing with the muscles because I never have any other troubles apart from the occasional headache (6) 
Others seemed to have incorporated the disease as part of who they are, although without 'being the disease'. Some perceived that the disease had influenced daily life to the extent that it had formed who the person is today. Not only negative but also positive aspects of living with LGMD2 were mentioned. These could include meeting people and making friends that one would not have done otherwise, finding motivation from the disease to do things and being able to spend more time with the family. Some of the participants said that they had become more humble and positive about life as well as more creative in solving practical difficulties:

I wouldn't have met the friends I have now if I hadn't had the disease ... it feels as if I would have been a completely different person ... I don't know whether I'm all that interested in what my life would have been otherwise because it wouldn't have been me and I'm quite content with myself (1)

\section{Health influenced by the disease and its consequences}

As the disease progressed, deteriorations in physical functions and mental strain were described.

\section{Experiences of physical functions varied}

Physical functions varied among the participants. Those who lived an independent life mentioned minor influences of the disease in daily life:

I'm affected by it (the disease) but not dramatically. It doesn't affect my everyday life (4) 
Those who were in transition to becoming more dependent described increased difficulty in performing activities, such as walking on a rough surface, climbing stairs, getting up after falling, bending down, rising from a chair and getting dressed. A wheelchair was occasionally used:

my balance is getting worse ... uneven surfaces are harder to walk on ... if I fell I wouldn't be able to get up ... it's hopeless to use stairs (6)

Dependency on other people and assistive devices to manage daily life was described by some of the participants. They had experienced deteriorated or loss of walking ability and a wheelchair was always used for ambulation. Weakness in the arms made it difficult or impossible to raise the arms:

When I walk I have support from the assistants and the walls ... I can walk a couple of metres and it goes slowly ... I'm really unsteady ... use a straw because I can't lift things ... I get help with clothes and in the shower... (14)

Complications from the heart and/or the respiratory system were described by a few of the participants. Two of them used continuous positive airway pressure (CPAP) as breathing support at night and experiences of having respiratory problems were described, such as difficulty in coughing and getting rid of mucus when having a cold. Contractions in the 
Achilles tendons and the elbows were also mentioned. Some of the participants described fatigue and/or pain, whereas others were without pain:

I'm in pain all the time ... a bit like muscle pains in the hands ... in the legs ... in the back ... it's like constant aches after exercise ... you feel tired all the time ... exhausted (10)

Despite living with a chronic disease, there was a sense of not being sick. Being sick was rather associated with periods of immersion into illness, caused by infections or additional diseases:

it might be a muscular disease but I don't look on myself as sick ... it's just the way it turned out (13)

\section{Experiences of mental strain}

Mental strain was sometimes described as more difficult to cope with than functional impairments and some of the participants had gone through periods of depression. Continuously having to cope and adjust to slow muscular deterioration was described as mentally difficult and could create worry about future health. At times, life with LGMD2 had aroused existential thoughts and troublesome emotions were described, such as sadness, anger, anxiety and frustration:

I suppose I find the mental part harder ... you don't really know where it will end ... and new things come up all the time that I have to deal with ... if you've dealt with one thing, three new ones come along (7) 
Some of the participants hoped that science would find a cure and that they would become healthy. The disease was viewed as an intruder that prevents a person from living life as preferred. Bodily limitations were perceived to have a major impact on everyday life and experiences of being physically and socially restricted were described:

you'd like to say that 'health is when you feel well and satisfied with yourself and happy' but I'm never that ... of course I can be happy and feel well, but I'm never satisfied with my body as long as I can't stand or walk or be healthy ... it will always feel as if I have my handicap (9)

Despite realizing the importance of finding and treating complications in time, follow-up controls at the hospitals were often thought to be mentally difficult since physical deteriorations may become obvious. Furthermore, some of the participants perceived that their personal thoughts and experiences of living with the disease were sometimes neglected by healthcare professionals:

you try to explain something but they (healthcare professionals) don't really listen ... you really are just one in the crowd there (2)

Mental strain was perceived to derive not only from the disease but also from the dependency on other people and external factors beyond the individual's immediate control. This could be access to support needed, the environment and attitudes in society towards people with disability. As the disease progressed, daily and social activities had to be coordinated with support required. Some of the participants had personal assistance around the clock, while 
others described being restricted in doing activities as a consequence of being denied or receiving insufficient hours of personal assistance:

you are really tied down ... I can't get away if I don't have help... I've applied several times (for personal assistance) but I get no help (12)

In addition, as physical impairment became obvious, the individual often became exposed to people's glances and comments. Some of the participants perceived being socially inhibited by negative attitudes in society. This feeling could be exacerbated when coming into a new context and meeting new people. Experiences of having a limited social network and being socially excluded were described. The perception was that being healthy somehow is the norm in society and there was frustration when having a sense of being categorized on the basis of the disease:

the disease affects me in everything and it's mostly the fault of other people, so it ought not to affect me socially the way it does ... I have no friends ... I'm on the outside all the time (8)

\section{Factors perceived to promote health}

Having an individual balanced lifestyle in terms of physical activity and healthy food habits as well as having social relations and meaningful daily activities were factors described as promoting health.

Finding a balanced lifestyle regarding physical activity and food habits 
The importance of finding a balanced lifestyle was described. It involved the balance between physical activity and food intake; healthy food habits and sometimes indulging oneself to eat unhealthy food; and physical activity without overdoing it:

looking after yourself ... moving as best you can, taking exercise, trying to eat right ... you have to try to maintain a balance between everything that makes you happy (2)

It was described as important to have a healthy diet and avoid becoming overweight in order to give the body the best conditions and thereby prevent additional difficulties for the individual and for people who assist in daily activities. However, several of the participants struggled to avoid or reduce weight gain. Physical activity including stretching was considered important to maintain physical functions and avoid stiffness and contractions. The intention was to find a balance between physical activities in accordance with ability but to avoid overwork since it can hasten the breakdown process in the muscles. Some of the participants had found a way to perform physical activities in accordance with the disease, for instance, by training in warm water. Others knew how to be physically active without overworking to a limited extent only and several of the participants did not receive regular physiotherapy. Difficulties, for instance, in stretching with support from a person who is not a physiotherapist were described. Also, training had to be balanced with other activities:

I can think, 'why haven’t I done more stretching?' ... but then, as always, I have chosen other things that I thought were more important or that made me feel better (13) 
Health was associated with having a supportive family and friends. It also implied a sense of being able to count on people no matter what happens. Some of the participants described themselves as outgoing and they found joy in meeting new people, whereas others preferred to be more at home and have time on their own:

Health for me is my family and my friends and meeting them and knowing that they're well (2)

Having meaningful daily activities

The participants described the importance of having a function and meaningful pursuits in their daily lives:

now I can see that an occupation or having a function is really important for health (1)

Given the opportunity to choose and decide what activities to do and how to perform them gave a sense of freedom. Some of the participants were working and employers who focused on qualifications instead of limitations were described. However, finding a job could be difficult because of physical impairment and being unemployed had negative economic effects. Also, several of the participants were unable to perform leisure activities as before because of physical deterioration. Some of the participants said they lacked meaningful activities: 'there's not much to do'; others were content with their daily pursuits.

\section{Self-rated SOC}


Self-rated SOC showed variation regarding where on the health-disease continuum the participants were located. The median score was 56 (range 37-77, mean 56). Participants described practical and mental struggles to cope with the disease and its consequences. Regardless of physical functions, however, those who scored $\geq 56$ more often expressed perceptions that may indicate a strong SOC, such as 'there are always new ways to manage' and 'having learned to live with it'. In general, they were satisfied with support received to manage daily life. Engagement in meaningful pursuits and having a social life outside the family were also described. In contrast, among those who scored $<56$ there were descriptions of being 'inhibited' to live a fulfilled life, not only because of the disease, but also because of lack of personal assistance and/or negative attitudes in society. These participants expressed more perceptions indicating a weak SOC, such as 'becoming more isolated' and 'the disease brings insecurity and uncertainty'. Those who scored the lowest SOC $(<40, N=3)$ were females dependent on support from other people. In the SOC-13 questionnaire they all stated that they 'have feelings inside they would rather not feel very often'.

\section{DISCUSSION}

This study is unique as it describes health perceptions related to self-rated SOC among young adults diagnosed with LGMD2. The main finding is that health was viewed as a subjective experience of intertwined physical and mental well-being with a sense of being satisfied with

life. As the disease progressed, however, health was described as being influenced by physical impairments and mental distress. Whereas some of the participants seemed to have achieved well-being with the disease incorporated as part of who they are, others expressed being constantly reminded and inhibited by the disease and its consequences. Factors perceived as 
promoting health were having a balanced lifestyle, social relations and meaningful activities. Those who scored the highest SOC lived an independent life and those who scored the lowest were dependent on support from other people.

Individuals diagnosed with LGMD2 need support from healthcare professionals to optimize their health. Young adults are in a time of identity exploration (Arnett 2004). Becoming physically weaker with increased dependency on others at a time when physical strength and independence are expected, combined with attitudes about physical disability in society, may have affected the participants' self-image and health perceptions. Previously, experiences of psychological consequences and deterioration of physical capacity over 10 years among adults diagnosed with different forms of MD has been described (Boström \& Ahlström 2004). In this study, various experiences related to the severity of the disease emerged. The perception was that personal concerns were sometimes neglected by caregivers, which caused frustration and worry. This highlights the importance of acknowledging the unique person in healthcare (Kristensson Uggla 2014). The importance of mental well-being, rather than physical abilities, was emphasized by some participants. Previous research shows that severe disability due to MD does not preclude health-related quality of life (Kohler et al. 2005), indicating that psychological factors may be more important in explaining well-being than physical functions. Incorporating chronic illness means that illness becomes a part of self and although the illness is intrusive and organizes life it does not entirely define or fill it (Charmaz 1997) as the person is able to cope with the disease (Antonovsky 1987). In this study, some of the participants scored a high SOC $(\geq 69)$ despite severe disability. Also, the perception was that a subjective experience of feeling healthy can be obtained regardless of physical ability. This finding is in accordance with the holistic theory of Nordenfelt (2007). Sometimes, however, the biostatistical perspective (Boorse, 1977) seems to dominate in healthcare and 
with a focus on pathological bodily processes that are objectively measurable there is a risk of overlooking the person's subjective health perceptions. When discussing health and disability, the two-dimensional theory (Tengland 2007) appears to be a reasonable theory. According to this theory, people can experience health despite disability, which is important to recognise in healthcare. They cannot, however, be regarded as fully healthy due to reduced abilities and this primarily has to do with the justification that society needs to support individuals with disabilities.

Well-being was perceived to be influenced not only by the disease but also by external factors. Those who scored a high SOC $(\geq 56)$ described more satisfaction with support received, daily pursuits and social life than those who scored a low SOC $(<56)$. According to the International Classification of Functioning, Disability and Health (WHO 2002) an individual's functioning can be viewed as a dynamic interaction between health conditions and contextual factors. Children, for instance, experience disability in terms of impairment, difference, other people's reactions and material barriers (Connors \& Stalker 2007). Antonovsky (1987) used the term generalized resistance resources to describe any characteristic of the person or the environment that can facilitate effective stress management, for instance, having a strong social network and meaningful pursuits. However, some of the participants in this study expressed a lack of meaningful activities and/or social relations, which has also been shown among young men with DMD (Abbott \& Carpenter 2014). According to Smith (2010), the human person must be understood as the unit of a corporeal body and an intangible soul. This in turn shapes the nature of social relations: bodily changes may influence social life. In addition, social structures that are generated to benefit those included are also at risk of excluding people (Smith 2010). The formation not only of the physical environment but also of social structures, for instance in the labour market or in the 
area of recreation, can be either a hindrance or a facilitator for people with disability to participate. The situation for people with chronic illness is thus complex and the solutions for management often lie beyond the healthcare system, such as access to personal assistance, transportation and finding meaningful activities (Charmaz 1997). There is a risk that the multifaceted needs of chronically ill people and the narrowness of the healthcare system undermine the best efforts of professionals to provide good care. This can cause frustration, not only for the individual but also for caregivers (Charmaz 1997). How then can healthcare professionals support young adults living with LGMD2 to optimize their health, given the complexity of their situation? In person-centred care (Ekman et al. 2011) the individual is viewed as a unique person with a unique body and respected both as vulnerable and as capable of making responsible decisions (Smith 2010). This not only means that the individual relies on a multidisciplinary healthcare team with knowledge about the diagnosis but also highlights the importance of acknowledging the individual's own perceptions of living with the disease. By listening to the individual, the perspective is shifted from what a patient is to who a person is (Kristensson Uggla 2014). Through dialogue, a partnership and shared decision makings can be developed between the person and healthcare professionals (Ekman et al. 2011).

\section{Limitations}

The SOC-13 questionnaire is not psychometrically tested for individuals diagnosed with MD in a Swedish context and the sample was limited. Also, the level of a normal SOC has not been specified (Antonovsky 1987) and SOC tends to increase with age (Feldt et al. 2011, Nilsson et al. 2010), which makes it difficult to know what the individual level of SOC at a given time really means in practice (Eriksson \& Lindström 2005). However, in this study the 
SOC-13 questionnaire was used to mirror qualitative data and thereby it strengthens the study. Although the findings are contextual and cannot be generalized, patterns in the findings might be transferable to similar groups in comparable contexts (Patton 2015).

The presence of the interviewer while answering the questionnaire might have influenced the participants but it was also an opportunity to pose questions, for instance, about how to mark their answers.

\section{CONCLUSION}

Health viewed as intertwined physical and mental well-being was perceived to be affected by reduced physical abilities and mental strain. The implication for healthcare is that care should be person-centred. Through dialogue, nurses should identify physical, psychological and social needs. The SOC-13 questionnaire may form the basis for a dialogue to assess how the individual comprehends, manages and finds meaning in everyday life and also highlight what support is needed to promote health. Caregivers should be a link to other authorities in society that provide services and to associations that might be of interest for the individual. 


\section{REFERENCES}

Abbott, D. \& Carpenter, J. (2014) 'Wasting precious time': young men with Duchenne muscular dystrophy negotiate the transition to adulthood. Disability \& Society, 29(8), 1192-1205.

Aho, A.C., Hultsjö, S. \& Hjelm, K. (2015) Young adults' experiences of living with recessive limb-girdle muscular dystrophy from a salutogenic orientation: an interview study. Disability \& Rehabilitation, 37(22), 2083-2091.

Ainsworth, B.E. \& Ananian, C.D. (2013) Wellness Matters: Promoting Health in Young Adults. Kinesiology Review, 2(1), 39-46.

Antonovsky, A. (1987) Unraveling the mystery of health: How people manage stress and stay well, Jossey-Bass, San Francisco.

Antonovsky, A. (2005) Hälsans mysterium (Unraveling the mystery of health), Natur \& Kultur, Stockholm.

Arnett, J.J. (2004) Emerging Adulthood: The Winding Road from the Late Teens Through the Twenties, Oxford University Press, New York.

Bengel, J., Strittmatter, R. \& Willmann, H. (1999) What keeps people healthy? Antonovsky's salutogenesis model; state of discussion and importance, Federal Centre for Health Education, Cologne.

Blomquist, K.B. (2006) Health, education, work and independence of young adults with disabilities. Orthopaedic Nursing, 25(3), 168-187.

Blum, R.W. (2005) Adolescents with disabilities in transition to adulthood In On Your Own without a Net. The Transition to Adulthood for Vulnerable Populations (Osgood, D. W., Foster, E. M., Flanagan, C. and Ruth, G. R. eds.) University of Chicago Press, Chicago, pp. 323-48.

Boorse, C. (1977) Health as a Theoretical Concept. Philosophy of Science 44(4), 542-573.

Boström, K. \& Ahlström, G. (2004) Living with a chronic deteriorating disease: the trajectory with muscular dystrophy over ten years. Disability and Rehabilitation, 26(23), 138898.

Bray, P., Bundy, A.C., Ryan, M.M., North, K.N. \& Everett, A. (2010) Health-related quality of life in boys with Duchenne muscular dystrophy: agreement between parents and their sons. Journal Of Child Neurology, 25(10), 1188-1194.

Breiner, H., Stroud, C., Bonnie, R.J. (2014) Investing in the Health and Well-being of Young Adults, National Academies Press, Washington.

Caap-Ahlgren, M. \& Dehlin, O. (2004) Sense of coherence is a sensitive measure for changes in subjects with Parkinson's disease during 1 year. Scandinavian Journal of Caring Sciences, 18(2), 154-159.

Charmaz, K. (1997) Good days, bad days: The self in chronic illness and time, Rutgers University Press, New Jersey.

Connors, C. \& Stalker, K. (2007) Children's Experiences of Disability: Pointers to a Social Model of Childhood Disability. Disability \& Society, 22(1), 19-33.

Delgado, C. (2007) Sense of coherence, spirituality, stress and quality of life in chronic illness. Journal of Nursing Scholarship, 39(3), 229-234.

Dreyer, P.S., Steffensen, B.F. \& Pedersen, B.D. (2010) Life with home mechanical ventilation for young men with Duchenne muscular dystrophy. Journal of Advanced Nursing, 66(4), 753-762.

Ekman, I., Swedberg, K., Taft, C., Lindseth, A., Norberg, A., Brink, E., Carlsson, J., DahlinIvanoff, S., Johansson, I.-L., Kjellgren, K., Lidén, E., Öhlén, J., Olsson, L.-E., Rosén, H., Rydmark, M. \& Sunnerhagen, K.S. (2011) Person-centered care - Ready for prime time. European Journal of Cardiovascular Nursing, 10(4), 248-251. 
Eriksson, M. \& Lindström, B. (2005) Validity of Antonovsky's Sense of Coherence Scale: A Systematic Review. Journal of Epidemiology and Community Health, 59(6), 460-466.

Eriksson, M. \& Lindström, B. (2006) Antonovsky's sense of coherence scale and the relation with health: a systematic review. Journal Of Epidemiology And Community Health, 60(5), 376-381.

Falk, K., Swedberg, K., Gaston-Johansson, F. \& Ekman, I. (2007) Fatigue is a prevalent and severe symptom associated with uncertainty and sense of coherence in patients with chronic heart failure. European Journal of Cardiovascular Nursing, 6(2), 99-104.

Feldt, T., Leskinen, E., Koskenvuo, M., Suominen, S., Vahtera, J. \& Kivimäki, M. (2011) Development of sense of coherence in adulthood: a person-centered approach. The population-based HeSSup cohort study. Quality of Life Research, 20(1), 69-79.

Ferris, M.E., Cuttance, J.R., Javalkar, K., Cohen, S.E., Phillips, A., Bickford, K., Gibson, K., Ferris, M.T. \& True, K. (2015) Self-Management and Transition Among Adolescents/Young Adults with Chronic or End-Stage Kidney Disease. Blood Purification, 39(1-3), 99-104.

Jetha, A., Badley, E., Beaton, D., Fortin, P.R., Shiff, N.J. \& Gignac, M.A.M. (2015) Unpacking early work experiences of young adults with rheumatic disease: An examination of absenteeism, job disruptions and productivity loss. Arthritis Care \& Research, 67(9), 1246-1254.

Kohler, M., Clarenbach, C.F., Böni, L., Brack, T., Russi, E.W. \& Bloch, K.E. (2005) Quality of life, physical disability and respiratory impairment in Duchenne muscular dystrophy. American journal of respiratory and critical care medicine, 172(8), 10321036.

Kristensson Uggla, B. (2014) Personfilosofi - fillosofiska utgångspunkter för personcentrering inom hälso- och sjukvård. In Personcentrering inom hälso- och sjukvård (Ekman, I. ed.) Liber AB, Stockholm, pp. 21-68.

Lim, Y., Velozo, C. \& Bendixen, R. (2014) The level of agreement between child self-reports and parent proxy-reports of health-related quality of life in boys with Duchenne muscular dystrophy. Quality of Life Research, 23(7), 1945-1952.

Mahmood, O.A. \& Xin Mei, J. (2014) Limb-girdle muscular dystrophies: Where next after six decades from the first proposal (Review). Molecular Medicine Reports, 9(5), 1515-32.

Mayring, P. (2000) Qualitative content analysis. Forum: Qualitative social research, 1(2), Art: 20.

Meleis, A.I. (2011) Theoretical nursing: development and progress, Lippincott Williams \& Wilkins, Philadelphia.

Narayanaswami, P., Weiss, M., Selcen, D., David, W., Raynor, E., Carter, G., Wicklund, M., Barohn, R.J., Ensrud, E., Griggs, R.C., Gronseth, G. \& Amato, A.A. (2014) Evidencebased guideline summary: diagnosis and treatment of limb-girdle and distal dystrophies: report of the guideline development subcommittee of the American Academy of Neurology and the practice issues review panel of the American Association of Neuromuscular \& Electrodiagnostic Medicine. Neurology, 83(16), $1453-1463$.

Nigro, V., Aurino, S. \& Piluso, G. (2011) Limb girdle muscular dystrophies: update on genetic diagnosis and therapeutic approaches. Current opinion in neurology, 24(5), 429-436.

Nilsson, K.W., Leppert, J., Simonsson, B. \& Starrin, B. (2010) Sense of coherence and psychological well-being: improvement with age. Journal of Epidemiology and Community Health, 64(4), 347-352.

Nordenfelt, L. (2007) The concepts of health and illness revisited. Medicine, Health Care and Philosophy, 10(1), 5-10. 
Olsson, M., Gassne, J. \& Hansson, K. (2009) Do different scales measure the same construct? Three sense of coherence scales. Journal of epidemiology and community health, 63(2), 166-167.

Opstal, S.L.S.H.v., Jansen, M., de Groot, I.J.M. \& van Alfen, N. (2014) Health-Related Quality of Life and Its Relation to Disease Severity in Boys With Duchenne Muscular Dystrophy: Satisfied Boys, Worrying Parents-A Case-Control Study. Journal of Child Neurology, 29(11), 1486-1495.

Park, M.J., Scott, J.T., Adams, S.H., Brindis, C.D. \& Irwin, C.E., Jr. (2014) Adolescent and young adult health in the United States in the past decade: little improvement and young adults remain worse off than adolescents. The Journal Of Adolescent Health: Official Publication Of The Society For Adolescent Medicine, 55(1), 3-16.

Parkyn, H. \& Coveney, J. (2013) An exploration of the value of social interaction in a boys' group for adolescents with muscular dystrophy. Child: care, health and development, 39(1), 81-89.

Patterson, P., Millar, B., Desille, N. \& McDonald, F. (2012) The unmet needs of emerging adults with a cancer diagnosis: a qualitative study. Cancer Nursing, 35(3), E32-E40.

Patton, M.Q. (2015) Qualitative Research \& Evaluation Methods: Integrating Theory and Practice SAGE Publications Inc, Los Angeles.

Pehler, S.-R. \& Craft-Rosenberg, M. (2009) Longing: The lived experience of spirituality in adolescents with Duchenne Muscular Dystrophy. Journal of pediatric nursing, 24(6), 481-494.

Rosales, X.Q. \& Tsao, C.-Y. (2012) Childhood onset of limb-girdle muscular dystrophy. Pediatric neurology, 46(1), 13-23.

Sandén-Eriksson, B. (2000) Coping with type-2 diabetes: the role of sense of coherence compared with active management. Journal of Advanced Nursing, 31(6), 1393-1397.

SFS (1982:763) Svensk författningssamling, Hälso- och sjukvårdslagen (The Swedish Health and Medical Services Act). Socialdepartementet, Stockholm.

Smith, C. (2010) What is a person?: Rethinking humanity, social life and the moral good from the person up, University of Chicago Press, Chicago.

Tengland, P.-A. (2007) A two-dimensional theory of health. Theoretical medicine and bioethics, 28(4), 257-284.

WHO (2002) The International Classification of Functioning, Disability and Health. World Health Organization, Geneva.

WMA (2013) World Medical Association. Declaration of Helsinki - Ethical Principles for Medical Research Involving Human Subjects. World Medical Journal, 59(5), 199202. 
Table 1. Overview of the categories and subcategories developed through data analysis in an interview study about health perceptions among young adults diagnosed with recessive limb-girdle muscular dystrophy.

\begin{tabular}{|c|c|c|}
\hline Category & Subcategory & Examples of transcribed text \\
\hline $\begin{array}{l}\text { Health viewed as well- } \\
\text { being }\end{array}$ & $\begin{array}{l}\text { Well-being with the disease } \\
\text { as part of life }\end{array}$ & it (the disease) is so normal now... everything works all right so I'm OK (5) \\
\hline \multirow[t]{2}{*}{$\begin{array}{l}\text { Health influenced by the } \\
\text { disease and its } \\
\text { consequences }\end{array}$} & $\begin{array}{l}\text { Experiences of physical } \\
\text { functions varied }\end{array}$ & $\begin{array}{l}\text { I'm affected by it but not dramatically. It doesn't affect my everyday life (4) } \\
\text { it's got worst with my legs ... there are maybe more things that I can't do such as } \\
\text { walking outdoors ... it's really difficult and steps will soon be nearly out of the } \\
\text { question (7) } \\
\text { and not being able to move, always needing somebody else to move me instead and } \\
\text { it's like talking to limbs instead of just moving them because I always have to get } \\
\text { somebody else to understand how I want to move them (8) }\end{array}$ \\
\hline & Experiences of mental strain & $\begin{array}{l}\text { sometimes it's not the muscles but my thoughts that are troublesome ... there are } \\
\text { periods when you really get into deep thoughts }(6)\end{array}$ \\
\hline \multirow[t]{3}{*}{$\begin{array}{l}\text { Factors perceived to } \\
\text { promote health }\end{array}$} & $\begin{array}{l}\text { Finding a balanced lifestyle } \\
\text { regarding physical activity } \\
\text { and food habits }\end{array}$ & $\begin{array}{l}\text { you can't do anything too difficult ... you can't feel pain afterwards ... that you feel } \\
\text { you've exerted yourself too much ... it's not good to be too comfortable either ... so } \\
\text { you must have a balance (6) } \\
\text { I am so completely terrified of putting on weight but I'm also really interested in } \\
\text { baking and sweet things ... so I associate health with keeping your weight ... it is so } \\
\text { hard ... such a balancing act ... I can't take a turn round the lake to lose the bun I } \\
\text { just ate ... (9) }\end{array}$ \\
\hline & Having close social relations & There are people I meet every day and have great fun with and then I feel well (5) \\
\hline & $\begin{array}{l}\text { Having meaningful daily } \\
\text { activities }\end{array}$ & an occupation or having a function is really important for health (1) \\
\hline
\end{tabular}


Table 2. Self-rated sense of coherence (SOC) among young adults diagnosed with recessive limb-girdle muscular dystrophy, related to demographic characteristics. The SOC-13 questionnaire developed by Antonovsky (1987) was used.

\begin{tabular}{|c|c|c|}
\hline $\begin{array}{l}\text { Demographic characteristics of the } \\
\text { participants* }\end{array}$ & $\begin{array}{l}\text { Number } \\
(\mathrm{N}=14)\end{array}$ & $\begin{array}{l}\text { Median score of } \\
\text { SOC-13 }\end{array}$ \\
\hline \multicolumn{3}{|l|}{$\begin{array}{l}\text { Dependency on other people/assistive devices to } \\
\text { manage daily life }\end{array}$} \\
\hline Independent & 2 & 74 \\
\hline $\begin{array}{l}\text { In transition from being independent to become } \\
\text { more dependent }\end{array}$ & 5 & 56 \\
\hline Dependent & 7 & 56 \\
\hline \multicolumn{3}{|l|}{ Living conditions } \\
\hline Living on their own & 4 & 59 \\
\hline Cohabiting & 4 & 62 \\
\hline Living with parents/other relatives & 6 & 56 \\
\hline \multicolumn{3}{|l|}{ Education } \\
\hline Completed upper secondary school & 10 & 56 \\
\hline Dropped out of upper secondary school & 4 & 54 \\
\hline Finished a university education & 3 & 72 \\
\hline \multicolumn{3}{|l|}{ Occupation } \\
\hline Working (full-time or part-time) & 4 & 74 \\
\hline Studying full-time & 4 & 48 \\
\hline Not working or studying & 6 & 54 \\
\hline
\end{tabular}

*Subtypes of LGMD2 represented were $2 \mathrm{~A}(\mathrm{n}=5), 2 \mathrm{~B}(\mathrm{n}=3), 2 \mathrm{E}(\mathrm{n}=1)$ and $2 \mathrm{I}(\mathrm{n}=5)$ 